\title{
The Impact of Implementing Steps of Empowerment Model on Decisional Conflict for Re-Pregnancy for Women with Failed Pregnancies: A Randomized Controlled Trial
}

\author{
MOZHGAN ZAREYEE SALEHABADI ${ }^{1}$, MASOOMEH KHEIRKHAH ${ }^{2}$, NAZANIN ESMAEELI ${ }^{3}$, SHIMA HAGHANI ${ }^{4}$ \\ ${ }^{1}$ Msc., Midwifery, Department of Reproductive Health and Midwifery, School of Nursing and Midwifery, Iran University of Medical Sciences, \\ Tehran, Iran. \\ ${ }^{2}$ Associate Professor of Nursing Care Research Center (NCRC), Department of Reproductive Health and Midwifery, School of Nursing and \\ Midwifery, Iran University of Medical Sciences, Tehran, Iran. Kheirkhah.m@iums.ac.ir, \\ ${ }^{3}$ Msc. Psychology, Iran University of Medical Sciences, Tehran, Iran. \\ ${ }^{4}$ Department of Biostatistics, School of Public Health, Iran University of Medical Sciences, Tehran, Iran. \\ Corresponding Author: Masoomeh Kheirkhah, Associate Professor of Nursing Care Research Center (NCRC), Department of Reproductive \\ Health and Midwifery, School of Nursing and Midwifery, Iran University of Medical Sciences, Tehran, Iran. \\ Email: Kheirkhah.m@iums.ac.ir, 09124787691. \\ Postal Address: School of Nursing \& Midwifery, Rashid Yasemi st., Valiasr St., Tehran, 1996713883, IRAN. \\ Fax: + (98-21) 88201978
}

\begin{abstract}
Background: Failed pregnancy is known as a common and destructive experience. It has physical and psychological effects on both women and their families. Due to this experience, they may become reluctant to be pregnant again. In this regard, providing the coping strategies can help in being adapted to failed pregnancies, and making informed decisions on future pregnancies. So, this study was designed and then performed to determine the effect of implementing steps of empowerment model on decision conflict for re-pregnancy for women with failed pregnancies

Method: This interventional research was a randomized controlled trial with a control group conducted in Iran from January 2020 to May 2020. Participants were 80 women who had been hospitalized in a referral center during the past 3-6 weeks due to failed pregnancies. Afterward, the eligible women were divided into the two groups of intervention $(n=40)$ and control $(n=40)$ with random allocation of sealed envelope site and a separate code was then determined for each person. The intervention was performed in four sessions lasted for 90-minute based on the model steps (threat perception, problem solving, educational participation, and evaluation) for intervention group. O'Connor's decisional conflict scale was completed in both groups once before and once six weeks after intervention. The obtained data were analyzed using SPSS edition 16 with the independent T-test, Fisher, and chi-squared tests.

Results The scores of decisional conflict and its subscales had no differences between the two groups before the intervention $(P=0.65)$. However, by passing six weeks from the intervention, the decisional conflict and all its subscales have reduced in the intervention group. $(P<0.001)$.

Conclusion: Empowerment education in women with failed pregnancies improved their decision conflict in immune re-pregnancy, so empowerment education along with health care services is recommended for women with failed pregnancies.

Trial registration: This randomized control trial was registered on the TCTR site with the code TCTR20191226001. Registered on 26 December 2019.

https://www.clinicaltrials.in.th/index.php?tp=regtrials\&menu=trialsearch\&smenu=fulltext\&task=search\&task2=view $1 \& \mathrm{id}=5336$

Keywords: Empowerment, Conflict, Decision Making, Failed Pregnancy.
\end{abstract}

\section{PLAIN ENGLISH SUMMARY}

Failed pregnancy, as a common experience, is shocking, especially to those who are unaware of the event. Many of these parents describe the loss of pregnancy as a critical event associated with worriedness and uncertainty about the outcomes of future pregnancies. Accordingly, this uncertainty consequently leads to decisional conflict. In general, decisional conflict is resulted from unawareness on personal values, risks, and benefits of choosing any option; feeling pressured by the others, and receiving no support in the selection process, which can be minimized using empowerment interventions. Therefore, the present study was conducted to assess the effectiveness of the implementing steps of empowerment model on decisional conflict in immune re-pregnancy for women with failed pregnancies. This interventional research was a randomized controlled trial with a control group conducted in Iran from January 2020 to May 2020. The participants were 80 women who had been hospitalized in a referral center during the past 3-6 weeks due to failed pregnancies. Thereafter, the eligible women were divided into two groups of intervention $(n=40)$ and control $(n=40)$ with random allocation sealed envelope site. The intervention was performed in four sessions lasted for 90-minute based on the model steps (threat perception, problem solving, educational participation, and evaluation) for the intervention group. For performing evaluation, O'Connor's decisional conflict scale was completed once before and once six weeks after the intervention in both groups. As demonstrated in the findings of this study, empowerment significantly improved decisional conflict in the intervention group compared to the control group. So, empowerment 
education along with health care services is recommended for women with failed pregnancies.

\section{BACKGROUND}

Unintended termination of pregnancy or loss of a pregnancy product from the beginning of pregnancy up to the birth time is called failed pregnancy (1), which can cause a lot of psychological stress to the family, and specifically to the mother herself as an influential and common experience (2).

About 1 in 6 recognized pregnancies annually results in miscarriage, and for every 200 births, 1 stillbirth takes place. In this regard, over 10000 ectopic pregnancies are diagnosed each year (3). So, $25 \%$ of all pregnancies result in miscarriage or stillbirth (4). Although 13 stillbirths have been reported per 1000 live births in Iran (5), accurate statistics on miscarriage rates in Iran are not available, and from 70.45 to 116.9 miscarriage are reported per 1000 live births (6).

The occurrence of a failed pregnancy can be shocking, especially for those who are unaware of the event (7). Most of these parents describe the loss of pregnancy as a critical event associated with vulnerability, anxiety, and uncertainty on the outcomes of future pregnancies (8). Although some of these women attempt to be well adapted to the situations occurred, others may suffer from long-lasting adaptation problems (9). Researchers have found that some causes of this nonadaptation are as follows: poor family and community support, lack of other children, mother's lack of selfconfidence, fear from husband separation, fear of the increased number of lost pregnancies, being ignored by the health care providers, having a record of infertility, and fear of re-pregnancy that can also exacerbate the problem (10). Generally, mothers with an experience fetal or neonatal death are reluctant to be pregnant again (11). Although repregnancy can have a positive effect on mental stress resulted from the loss of pregnancy (12), the feeling of doubt and hesitation in parents with who experienced a lost pregnancy is multiplied by the fear of losing the pregnancy again (9). In general, decisional conflicts can be resulted from some factors such as uncertainty and unawareness on personal values, risks and benefits of choosing each option, feeling pressured by others, receiving no support in choosing, and unawareness on alternatives that can be minimized with educational and supportive interventions (13). A systematic review by Stacey et al. (2017) showed the effectiveness of some decision support methods such as pamphlets, videos, the internet tools, and training in the face of hesitation and conflict in health care and screening decisions regarding awareness, individual values, decision support, satisfaction, and confidence to make the decision (14).

On the other hand, it is very important to be medically and emotionally prepared for another pregnancy (15). Allahdadian et al. (2019) in an interview with a number of such women have found that most of these mothers had no information on preparing for next pregnancy and preventing from happening the loss of pregnancy again (16). The best way to improve the situation of parents with a failed pregnancy, is listening to them, spending time for them, to give them awareness and information, to involve them in making relevant decisions, and to take their concerns seriously (17). By empowering, individuals can identify the problem roots as well as its consequences, make decisions to find solutions for the problem, and can also consider themselves as responsible for changing their behavior (18). Currently, our question is whether empowering women with a history of failed pregnancies can reduce their decisionmaking conflict regarding trying to conceive again. Accordingly, one of the patterns of local empowerment in Iran is the model of Alhani empowerment. In this model, indicators of empowerment involve the followings: 1) perceived threat, awareness on the complications, and problems related to a particular disease or health condition; 2) problem solving by the individual by performing preventive behaviors, reacting appropriately, and creating a sense of self-efficacy, trust, and confidence in self-care; 3) Educational participation of the people involved (19), improvement of one's self-esteem and positive attitude towards oneself and self-control, and increasing the sense of responsibility towards behaviors; and 4) behavior evaluation. Moreover, in implementing this model, emphasis is mostly placed on responsibility and cooperation with a focus on existing capacities; therefore, this model is likely to be a good practical solution in promoting self-care (20). Currently, training classes are held for Iranian pregnant women, but despite the obvious importance of empowering the injured women with failed pregnancies, there are no guidelines for empowering these women and their families, yet. Given the importance of improving the health of mothers and future generations, according to the midwives' roles in the psychological and emotional supports of women and families in all dimensions, and because of the availability of midwives for these women, the research team of this study aimed to determine the effect of implementing empowerment model steps (perceived threat, problem solving, educational participation, and evaluation) (21), on decisional conflict in immune re-pregnancy in women with failed pregnancies.

\section{METHODS}

Trial design: This research was an interventional study of a randomized controlled trial with two parallel groups (Intervention and control groups).

Participants: This study was conducted in Shahid Akbarabadi Educational and Medical Center in Tehran, Iran. All women aged between 18 and 40 years old with a history of failed pregnancy who had been admitted to Shahid Akbarabadi hospital for termination of pregnancy in the last 3-6 weeks could be included in this study, if they meet the inclusion criteria. Iranian married women without any child who were literate, had no medical ban on pregnancy, had no infertility problems, had a history of pregnancy loss up to 2 cases, no pregnancy history after the recent failed pregnancy, and no history of mental illness or taking drugs and psychotropic substances were eligible to enter this study. Women who met the inclusion criteria but became pregnant or experienced any stressful event such as divorce, financial crisis, the death of a first-degree family member, or those who missed more than one training session were excluded from the trial.

Study Instrument: Data collection tools included demographic questionnaire containing 17 questions (age, 
education and employment status of couples, economic status, duration of the marriage, number of pregnancies, age of women at the time of the first pregnancy, reason of failed pregnancy, the gender of the lost fetus, number of lost pregnancies, delivery type, and the current preferred method of contraception) and O'Connor's Decisional Conflict Scale that includes a question on the person's choice of pregnancy in the future, and 16 questions with five decisional sub-domains (three questions on the informed subscale, three questions on value clarity, three questions on decision support, three questions on confidence sub-domain, and finally four questions on an effective decision). In addition, according to the questionnaire guideline, the questions can be rate with a 5point scale as follows: yes (0), possibly yes (1), uncertain (2), possibly no (3), and no (4). In each one of the subdomains, the sum of the scores of the questions was firstly calculated and then divided by the number of questions. Afterward, the division result was multiplied by 25 , and scores' range was from zero to 100 . In summing up the scores, the closer the total score to 100, the more the conflict signs (uncertain and delayed decisions), and the lower the scores, the less the decisional conflict (the more confident decisions) (zero was a sign for non-conflict in decision-making and 100 was a sign for the maximum decisional conflict).

The original version of the decisional conflict questionnaire, which contains 16 questions to review decision-making, was firstly developed by O'Connor (1993), revised in 2005, and then updated in 2010. For the original version of this tool, optimal validity and correlation were reported using the optimal re-testing method and the Cronbach's alpha coefficient was calculated as 0.78 (22). In a study by Ghiyasvandian et al. (2013), the validity of the decisional conflict scale was calculated with Cronbach's alpha coefficient of 0.94 (23). Moreover, Moudi et al. (2018) reported tool reliability as 0.92 (24).

In this study, the content validity was used to determine tool validity. In addition, for face validity, the decisional conflict tool was given to 20 women with failed pregnancies and the levels of difficulty (difficulty in understanding words and phrases) and ambiguity (possible misunderstandings on phrases or semantic incompatibility of words) were also identified. Furthermore, the reliability of this study was evaluated using two methods of Cronbach's alpha and test re-test. Accordingly, these tools were given to 20 women with failed pregnancies, which were then given to them again two weeks later. Also, the internal correlation of the questions was calculated with Cronbach's alpha coefficient of 0.869 . Correspondingly, it was 0.749 for the subscale of awareness, 0.734 for the subscale of individual values, 0.655 for decision support, 0.710 for confidence, and 0.778 for effective decision-making. Moreover, repetition by Pearson correlation coefficient for the total instrument of decisional conflict was calculated as $0.986,0.946$ for subscales of awareness, 0.967 for recognition of individual values, 0.901 for decision support, 0.946 for confidence, and 0.993 for effective decisions.

Intervention: This study was conducted on 80 women who had been hospitalized during the past 3-6 weeks due to fail pregnancy, from January 2020 to May 2020. To select the samples, with the permission of the hospital management, the researcher continuously referred to the hospital's medical records unit, and then extracted the women's names with failed pregnancies in the last 3-6 weeks. Thereafter, the researcher called them by phone, and then selected the eligible participants to enter the study. After explaining the objectives of the study to the subjects, as well as the educational content, the number of training sessions, and the possible results and applications, they were invited to participate in this project on a specific day, date, and time. The participants in the project were assured that all information would be kept confidential and the written informed and free consent was obtained from all of them before random allocation. Prior to the study beginning, the demographic questionnaire and the decisional conflict scale were distributed among all participants to be complete (the controls and interventions) in an appropriate position, and in a quiet place in the research environment. In cases that the research units needed explanations for the completion of the questionnaire, the guidelines were provided by the researcher. After the collection of the questionnaires before the intervention, the implementation method of the plan and its purpose were described in details to the subjects. The educational content was then prepared using reference books and the related descriptive articles, and accordingly, its validity was approved by 5 faculty members of Iran University of Medical Sciences. Participants of the control group were asked to leave the hospital and to wait for a reinvitation in the next 9 weeks for completing the questionnaires again. On the same day, the first empowerment training session was performed based on the four steps (threat perception, problem solving, educational participation, and evaluation) in four sessions lasted for 90-minute (training sessions and group discussion) over 4 consecutive weeks in 4 groups of 8-12 people in a training class of the Akbarabadi educational and medical center. The date and time of the next meeting were fixed with the intervention group. In this regard, the empowerment support training program was implemented in the two groups using questions and answers, slide shows, and presentation of a summary of the discussed topics related to each session in the form of pamphlets. To increase the threat perception of the samples, it was necessary to increase the subjects' levels of knowledge and understanding of a failed pregnancy and its reasons, which were improved during the training sessions. Problem-solving sessions were conducted by participating a team including midwifery and psychology specialists, and by providing coping and adaptations strategies. Also, the introductions of the selected options were assisted to find solutions by the women themselves and to increase their self-efficacies. Knowledge, ability, and support helped them to increase their self-esteem. Along with increasing selfefficacy and self-esteem, self-control has also improved. To increase educational participation, at the end of each session, an educational pamphlet was provided to the participants. Afterward, to implement the fourth step of the empowerment model (evaluation), the researcher evaluated the process during the sessions of intervention, and at the beginning of each session (examining the degree of listening, attention, learning, interest, and mental participation). Ultimately, the final evaluation was 
performed by passing 6 weeks from the end of the intervention by re-completing the decisional conflict scale

Table 1

Program of training sessions for the intervention group by both control and intervention groups. (Table 1).

\begin{tabular}{cl}
\hline Sessions & List of educational materials based on empowerment steps \\
\hline 1 & Greeting, defining failed pregnancy, help to emotional evacuation by \\
personally describing the event and sharing the experience of loss and \\
stating the dysfunctional beliefs (the threat perception), providing \\
educational pamphlets for samples (educational participation). \\
Fetal death and its causes, accepting reality, increasing understanding \\
of the event (threat perception), ways to correct cognitive errors, \\
managing emotions (problem solving), providing educational \\
pamphlets for samples (educational participation). \\
Strategies for controlling physical and mental conditions, self-care \\
methods and self-control and coping strategies (social support), \\
description of reproductive process, decision making (problem \\
solving), providing educational pamphlets for samples (educational \\
participation). \\
Goal setting, attention to individual values, self-awareness, decision- \\
making skills, finding solutions by women themselves and helping to \\
make informed decisions (problem solving), maternal attachment to \\
the fetus, necessary measures before re-pregnancy, (information \\
support), providing educational pamphlets for samples (educational \\
participation).
\end{tabular}

\section{Sample Size}

The sample size was calculated using the following formula:

$$
\begin{aligned}
n=\frac{2 *\left(z_{1-\alpha / 2}+z_{1-\beta}\right)^{2}}{E . S^{2}} & =\frac{2 *(1.96+0.84)^{2}}{(0.7)^{2}}=32 \\
z_{0.95} & =1.96 \\
z_{0.8} & =0.84
\end{aligned}
$$

The sample size by taking into account the level of confidence of $95 \%$ and the test power of $80 \%$ and considering Cohen's effect size on the average on the decisional conflict variable in the intervention group was calculated to involve 32 women. In the control group (ES =
0.7 ), it was finalized to involve 40 people, including a $25 \%$ drop in the sample size in each group.

\section{RANDOMIZATION}

Each participant was given a number according to the list of the eligible participants included in this study, and was 
then provided a random list for two groups from Sealed Envelope site (25). In the sealed envelope site, we used simple randomization service based on block identifier, block size, sequence within the block, and group code. A list was created and generated a unique randomization code, with block sizes of 4, 6, and 8. Then, we used a saved copy of this list to look up the intervention group for the given code. The eligible women with failed pregnancies based on a random list, were assigned into two groups as the control (routine group, $n=40$ ) and intervention (empowerment group, $n=40$ ). On the day of the clients' visit, the list was given to a colleague who was not involved in the plan (secretary of the clinic), in order to put the names of the samples in rank of entering the meeting place in the list. In this way, the samples were placed in two groups of intervention and control, completely by accident and without knowing about the classification process, neither by the participants nor by the researcher. The researcher's full name and telephone number were provided to the subjects to inform the researcher in case of any problem or question. Notably, the study was conducted in terms of the Consolidated Standards of Reporting Trials (CONSORT) guidelines (26) (Fig1)

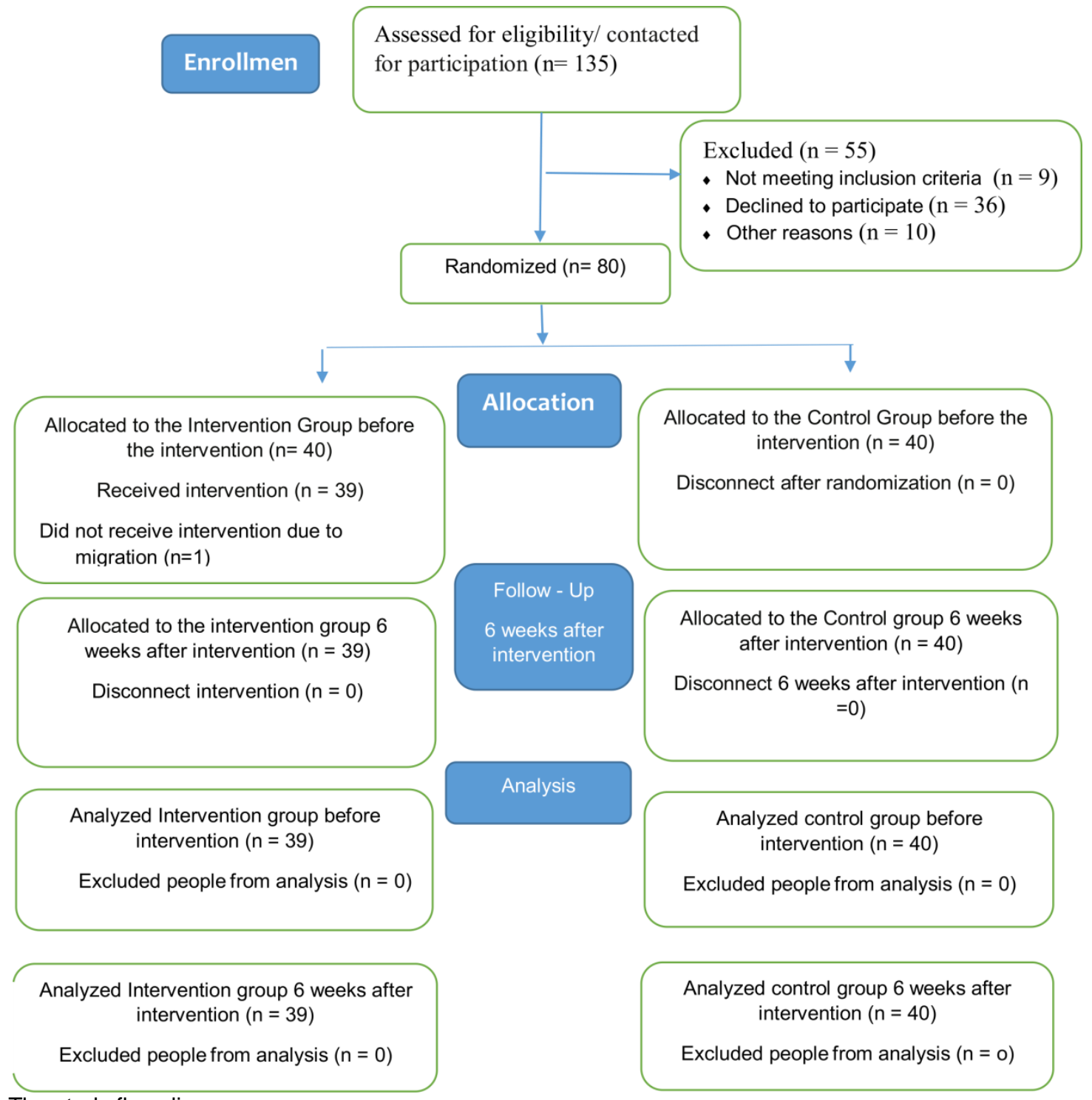

Figure 1: The study flow diagram

Statistical methods: Data analysis was performed using SPSS version 16 and the descriptive statistics such as frequency tables, and numerical indicators; and inferential statistics such as Fisher's statistical tests, chi squared, independent T-test, and paired T-test were performed.
Also, the significant level in this study was considered as ( $p$ $<0.05)$.

\section{RESULTS}

Of the total 80 women participating in this study (40 in the intervention group, and 40 in the control group) one subject 
in the intervention group was excluded due to nonparticipation in training sessions due to migration, and the data analysis was performed in the two groups.

The mean age of the women in the intervention group was $29.71 \pm 5.45$ years old and in the control group was $30.27 \pm 6.25$ years old. There was no statistically significant difference among the participants between these two groups in terms of demographic information and pregnancy characteristics including age, educational level and occupation of the couples, economic status, duration of marriage, number of pregnancies, age of the woman during the first pregnancy, cause of failed pregnancy, gender and age of the missing fetus, number of missed pregnancies, termination of pregnancy method, and the current method of contraception. (Table 2).

In the intergroup comparison, the independent T-test indicated no conflict between women's decision-making in the two groups before the intervention $(p=0.65)$. The decisional conflict score in the intervention group decreased in all five sub-scales (informed, value clarity, decision support, confidence, and effective decision) by passing 6 weeks from the intervention, which was significantly different compared to the control group ( $p$ $<0.001)$. Accordingly, this means that the awareness of the women in the intervention group on the options, and the advantages and disadvantages of each choice after intervention was higher compared to the control group. Among women in the intervention group, the scores on recognition of individual values, enjoying social support, confidence in decision-making, and choice were higher. Moreover, there was less doubt and hesitation after intervention during decision-making in the intervention group compared to the control group. In the intragroup comparison, the paired T-test in the intervention group showed a conflict score before and after the intervention ( $p$ $<0.001$ ) (Table 3).

Prior to the intervention, 67.5 percent of the subjects of the control group and 48.7 percent of the subjects of the intervention group had chosen the option "I would not like to become pregnant right now", and the two groups showed no statistically significant difference. The comparison of the type of option selected by the women was significant after the intervention between these two groups, in which the majority of the samples in the intervention group selected the option "I would like to become pregnant again." Also, most of the studied subjects in the control group selected the option "I would not like to become pregnant right now" $(p<0.001)$ (Table 4). 


\section{ORIGINAL ARTICLE}

Table 2

Demographic and pregnancy characteristics of women and their husbands and comparison of the two groups

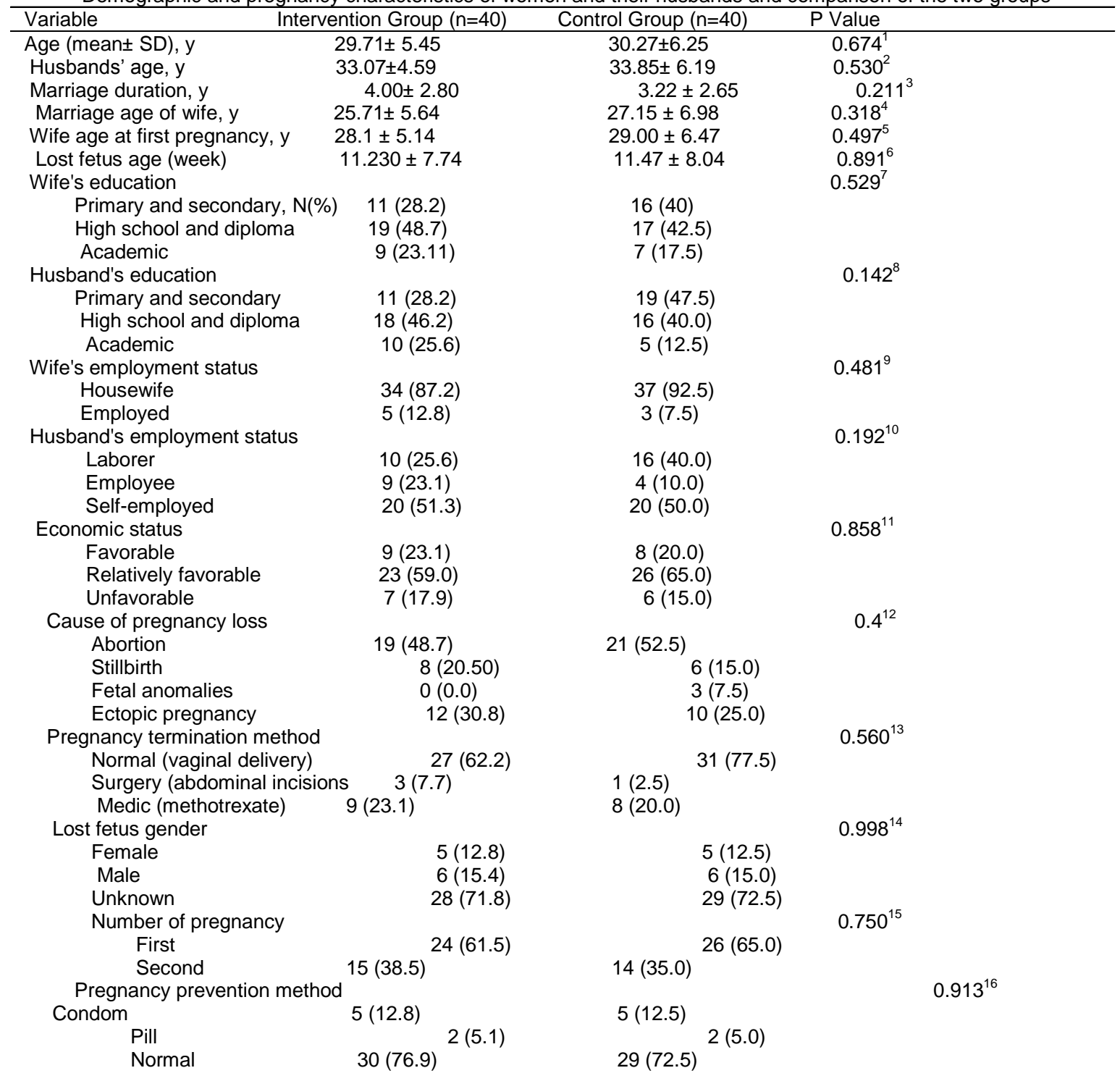

$1234,5,6$ Independent-T test

7 ' $^{\prime}$ ' 11 ' 1 1 4 ' 15 Chi-square test

$9,10,12,13,16$ Fisher's exact test 


\begin{tabular}{|c|c|c|c|c|}
\hline Economic status & & & $0.858^{1}$ & \\
\hline Favorable & $9(23.1)$ & $8(20.0)$ & & \\
\hline Relatively favorable & $23(59.0)$ & $26(65.0)$ & & \\
\hline Unfavorable & $7(17.9)$ & $6(15.0)$ & & \\
\hline Cause of pregnancy loss & & & $0.4^{2}$ & \\
\hline Abortion & $19(48.7)$ & $21(52.5)$ & & \\
\hline Stillbirth & $8(20.50)$ & $6(15.0)$ & & \\
\hline Fetal anomalies & $0(0.0)$ & $3(7.5)$ & & \\
\hline Ectopic pregnancy & $12(30.8)$ & $10(25.0)$ & & \\
\hline Pregnancy termination method & & & $0.560^{3}$ & \\
\hline Normal (vaginal delivery) & $27(62.2)$ & $31(77.5)$ & & \\
\hline Surgery (abdominal incisions & $3(7.7)$ & $1(2.5)$ & & \\
\hline Medic (methotrexate) & $9(23.1)$ & $8(20.0)$ & & \\
\hline Lost fetus gender & & & $0.998^{4}$ & \\
\hline Female & $5(12.8)$ & $5(12.5)$ & & \\
\hline Male & $6(15.4)$ & $6(15.0)$ & & \\
\hline Unknown & $28(71.8)$ & $29(72.5)$ & & \\
\hline Number of pregnancy & & & $0.750^{5}$ & \\
\hline First & $24(61.5)$ & $26(65.0)$ & & \\
\hline Second & $15(38.5)$ & $14(35.0)$ & & \\
\hline Pregnancy prevention method & & & & $0.913^{6}$ \\
\hline Condom & $5(12.8)$ & $5(12.5)$ & & \\
\hline Pill & $2(5.1)$ & $2(5.0)$ & & \\
\hline Normal & $30(76.9)$ & $29(72.5)$ & & \\
\hline No methods & $2(5.1)$ & $4(10.0)$ & & \\
\hline
\end{tabular}

$\begin{array}{llllll}1 & 2 & 3 & 4 & 5 & 6 \\ & & & & & \\ 7 & & & \end{array}$

$7^{\prime} 8^{\prime}, 11^{\prime} 1_{4}^{\prime}, 15$ Chi-square test

$9,10,12,3,16$ Fisher's exact test 
Table 3

The effect of intervention on the decisional conflict scale among samples

\begin{tabular}{|c|c|c|c|c|}
\hline Sub-scales & Evaluation time & $\begin{array}{c}\text { Intervention } \\
\text { Mean } \pm S D \\
\end{array}$ & $\begin{array}{ll}\text { Control } & \text { Independ } \\
\text { Mean } \pm \text { SD } & \\
\end{array}$ & t T-test \\
\hline \multirow[t]{2}{*}{ Informed } & Pre- intervention & $58.76 \pm 24.77$ & $87 \pm 23.30$ & $P=0.20$ \\
\hline & $\begin{array}{l}\text { Post- intervention } \\
\text { Paired T-test }\end{array}$ & $\begin{array}{l}17.9 \pm 16.50 \\
P<0.001\end{array}$ & $\begin{array}{l}54.37 \pm 24.38 \\
P=0.16\end{array}$ & $P<0.001$ \\
\hline \multirow{2}{*}{$\begin{array}{l}\text { Values Clarity } \\
0.46\end{array}$} & Pre- intervention & $51.92 \pm 22.65$ & $55.83 \pm 24.10$ & $\mathrm{P}=$ \\
\hline & $\begin{array}{l}\text { Post- intervention } \\
\text { Paired T-test }\end{array}$ & $\begin{array}{c}21.58 \pm 16.52 \\
P<0.001\end{array}$ & $\begin{array}{c}57.70 \pm 23.06 \\
P=0.07\end{array}$ & $P<0.001$ \\
\hline Decision support & $\begin{array}{l}\text { Pre- intervention } \\
\text { Post- intervention } \\
\text { Paired T-test }\end{array}$ & $\begin{array}{l}52.77 \pm 20.35 \\
16.88 \pm 17.98 \\
P<0.001\end{array}$ & $\begin{array}{l}51.66 \pm 23.12 \\
52.70 \pm 23.74 \\
P=0.36\end{array}$ & $\begin{array}{l}P=0.82 \\
P<0.001\end{array}$ \\
\hline Confidence & $\begin{array}{l}\text { Pre- intervention } \\
\text { Post- intervention } \\
\text { Paired T-test }\end{array}$ & $\begin{array}{c}54.05 \pm 22.36 \\
23.93 \pm 22.71 \\
P<0.001\end{array}$ & $\begin{array}{l}60.20 \pm 19.65 \\
59.16 \pm 22.15 \\
P=0.34\end{array}$ & $\begin{array}{l}P=0.19 \\
P<0.001\end{array}$ \\
\hline Effective decision & $\begin{array}{l}\text { Pre- intervention } \\
\text { Post- intervention } \\
\text { Paired T-test }\end{array}$ & $\begin{array}{l}42.94 \pm 21.32 \\
18.75 \pm 21.26 \\
P<0.001\end{array}$ & $\begin{array}{l}48.28 \pm 19.04 \\
47.96 \pm 18.20 \\
P=0.75\end{array}$ & $\begin{aligned} P & =0.24 \\
P & <0.001\end{aligned}$ \\
\hline Total & $\begin{array}{l}\text { Pre- intervention } \\
\text { Post- intervention } \\
\text { Paired T-test }\end{array}$ & $\begin{array}{c}51.52 \pm 17.22 \\
19.75 \pm 17.10 \\
P<0.001\end{array}$ & $\begin{array}{c}53.24 \pm 17.04 \\
53.98 \pm 17.05 \\
P=0.19\end{array}$ & $\begin{array}{l}P=0.65 \\
P<0.001\end{array}$ \\
\hline
\end{tabular}

Table 4

Frequency of options selected by women with failed pregnancies in relation to again pregnancy

\begin{tabular}{lcccc}
\hline \multicolumn{4}{c}{ Choices } & \multicolumn{3}{c}{ Before } & \multicolumn{3}{c}{ After } \\
& $\mathrm{N}(\%)$ & $\mathrm{N}(\%)$ & $\mathrm{N}(\%)$ & $\mathrm{N}(\%)$ \\
\hline I would like to become pregnant again. & $6(15.4)$ & $7(17.5)$ & $30(76.9)$ & $6(15)$ \\
I would not like to become pregnant right now. & $19(48.7)$ & $27(67.5)$ & $7(17.9)$ & $27(67.5)$ \\
I never become pregnant & $14(35.9)$ & $6(15)$ & $2(5.1)$ & $7(17.5)$ \\
Test results & \multicolumn{2}{c}{$\mathrm{P}=0.097$} & $\mathrm{P}<0.001$ & Control \\
\hline
\end{tabular}

\section{DISCUSSION}

Decisional conflict and contradiction in re-pregnancy has significantly reduced among the women in the intervention group after empowerment compared to the control group. In addition, as it was observed, decisional conflict after training was significantly lower than that of before training, and empowerment training affect was on reducing the decisional conflict. The results of the present study are consistent with the results of a systematic review performed by Stacey et al. (2017), which aimed to examine the effect of decision support methods on healthcare and screening decisions. In this study, the decision aid methods included pamphlets, videos, the Internet tools, and training on 50 decisional issues in the following fields: surgery, prostate cancer screening, colon cancer, prenatal, and genetic testing. In these studies, decision support in various ways had reduced decisional conflict in some dimensions such as feeling unaware, hesitation in individual values, lack of decision support, and decision dissatisfaction and uncertainty. also, the increased accuracy of the perception of risks and complications, more transparency in individual values, and individual involvement in decision-making were some results of the reduced decisional conflict, which are consistent with the results of the recent research (14). The results of a similar study by Meade et al. (2015) showed that the decisional conflict and hesitation to become pregnant after the intervention have reduced by $15 \%$ compared to the control group ( $p<0.001$ ), and the intervention group felt support for decision-making (27). Moreover, the results of a study by Moudi et al. (2018) were also in line with the results of the present study. The decisional conflict of women in deciding to terminate the pregnancy has reduced after counseling on all following subscales: awareness, transparency of values, confidence, support, and effective decision, and it was also decided to terminate the pregnancy with less conflict (24). In another study, Carlson et al. (2019) have also studied the effect of computer-aided decision-making on decisional conflict on aneuploidy screening. Accordingly, it was shown that the decisional conflict in the intervention group decreased after receiving the computer aided decision-making to perform aneuploidy screening ( $p<0.003$ ) (28). The decision aid methods such as education and counseling to raise awareness can help people to better understand their personal values, to participate in the decisions, and to make better decisions with more certainty based on the available evidence and options with the support of health care providers and families, and without being forced to make decisions. 
One of the goals of health for all people in the $21^{\text {st }}$ century is empowerment. In this regard, empowerment is defined as the process of improving self-confidence, awareness, and decision-making skills to increase health and health care levels and to improve life quality. Moreover, a key component of empowering people is to participate in helping themselves and having control and ability to achieve empowerment goals (29). Accordingly, the individuals' participation in health care and selfmanagement is mostly emphasized. Correspondingly, participation in health care is a reciprocal relationship between the individuals and the health care system or health care staff, during which the individuals participate in the provision of information to help in diagnosing and resolving the problem, and to play an active role regarding that (30). Also, in recent decades, the main approach of health was providing awareness and necessary training to change individuals (31). In this regard, empowerment can be named, which is a low-cost and practical method that can be performed by developing the individuals' innate capacity to accept life responsibility by having sufficient knowledge and resources to make and implement logical decisions and also to evaluate the effectiveness of their decisions (32). One of the empowerments patterns is the Iranian model of empowerment that is performed in four steps (threat perception, problem-solving, participation in education, and evaluation) (33). Due to this model, plans are taken for empowering and participation of empowering and then empowered to reduce risk factors and promote health, which emphasize on capacities more than problems and shortcomings (34). In addition, the main goal of the family-centered empowerment model is to empower the family system (the patient and other family members) to improve their health levels (31). Accordingly, one of the families' members, as an " active family member" who has the characteristics of desire and decision-making power, and is able to cooperate, would participate in the empowerment process, and then the person would be empowered in the family system to promote health and hygiene (19). A planned and systematic training will increase the levels of information, self-care, and satisfaction of people and also reduce their level of anxiety. (35) The results of a study by Kheirkhah et al. (2014) have also shown that holding group counseling sessions were effective on being adapted to infertility in infertile women (36). Notably, it is difficult to decide on the best choice, especially when there are multiple options and the result is in a state of ambiguity, or in a situation when the choices are accompanied by advantages and disadvantages that do not have equal values for different individuals. Parents who experience failed pregnancies always feel a sense of hesitation in attempting to conceive again, because of the fear of losing their pregnancy again (13). By providing awareness for the individual and the family on the illness and crisis, complications, treatment, and self-care methods, individuals can be prepared to play active and independent roles in their decisions.

The limitations of this study were as follows: lack of participation of the fathers in the educational sessions, which did not allow us to discover their beliefs, as well as the impact of their views and opinions on their wives' decisions. Also, because of not holding the meetings for men, women's participation in classes was associated with some problems. So, to solve these problems, the researcher called the participants the day before each meeting, and while reminding them the time of the meeting by re-stating the objectives, motivated them to participate in the meeting. Meanwhile, due to time constraints on the implementation of the plan, the persistence of conflict reduction in the decision to become pregnant and the final result of taking or not taking action to be pregnant again was not followed-up. Additionally, since 3-6 weeks had passed from the loss of pregnancy, some mothers became indifferent and unmotivated about the event and did not easily agree to express their feelings. It is worth noting that our analysis was made based on a small sample size, so our study may not be generalized. Finally, it is proposed to begin empowerment with the provision of educational and supportive-psychological interventions besides providing the medical-care services for women with failed pregnancies as well as their husbands from the very first days of the loss.

\section{CONCLUSION}

According to this research results, educational and supportive interventions and empowerment can minimize decisional conflict in immune re-pregnancy in women with failed pregnancies. Given that midwives are the most accessible individuals for these injured women, and since no guidelines are currently implemented in hospitals and comprehensive health care centers for empowering these women as well as their families after failed pregnancies, proposing an empowerment protocol to guide, support, and educate along with caring them would help this injured people to make the right decisions.

Abbreviation: Not applicable

\section{Declaration}

\section{Ethics approval and consent to participate}

Approval to conduct the study was obtained from the Research Ethics Committee of Iran University of Medical Sciences NO. IR.IUMS.REC.1397.1327, registration of the trial on the TCTR site with the code TCTR20191226001, and obtaining the necessary licenses from Iran University of Medical Sciences. Written informed consent was obtained from the participants. Furthermore, the women were informed that they had the right to withdraw from the study at any time, and were assured of the confidentiality of the study.

Consent for publication: Not applicable (we have not included names, images or videos of participants that need obtaining consent).

Availability of data and materials: The datasets used and/or analyzed during the current study are available from the corresponding author on reasonable request.

Competing interests: "The authors declare that they have no competing interests."

Funding: The Iran University of Medical Sciences funded this study as a part of an MSc Thesis. [grant numbers. 981-3-14233].

Authors' contributions: All authors were involved in the study conception, designing, and drafting of the manuscript. MZS: Writing and the initial translation of the article and sampling, MKH :Writing and the final approval of the article and direct supervision of the research process 
including supervising the writing of the proposal, and educational content, NE: Psychological counseling on the process of empowering mothers with unsuccessful

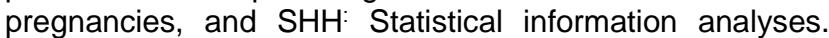
Also, all authors have read and approved the final version of the manuscript.

Acknowledgment: This article is a part of a master's thesis in midwifery, reproductive health, and the research project of Iran University of Medical Sciences, No. 98-1-314233. We are greatly thankful to the postgraduate studies' section of the university, the vice-chancellor for research in the School of Nursing and Midwifery of Iran University of Medical Sciences, the Shahid Akbarabadi Clinical Research Development Unit (ShACRDU), Iran University of Medical Science (IUMS), Tehran, Iran, and all the women who participated in the implementation and completion of this research.

\section{REFERENCES}

1. Bhat $A$, Byatt N.Infertility and perinatal loss: when the bough breaks. Current psychiatry reports. 2016;18(3):31.

2. Simwaka A, De Kok B, Chilemba W.Women's perceptions of Nurse-Midwives' caring behaviours during perinatal loss in Lilongwe, Malawi: an exploratory study. Malawi medical journal. 2014;26(1):8-11.

3. Littlemore J, Turner S.Metaphors in communication about pregnancy loss. Metaphor Soc World. 2019.

4. Hutti MH, Armstrong DS, Myers J.Evaluation of the perinatal grief intensity scale in the subsequent pregnancy after perinatal loss. Journal of Obstetric, Gynecologic \& Neonatal Nursing. 2013;42(6):697-706.

5. Yang L, McCall B.World education finance policies and higher education access: A statistical analysis of World Development Indicators for 86 countries. International Journal of Educational Development. 2014;35:25-36.

6. Rastegari A, Baneshi MR, Haji-Maghsoudi S, Nakhaee N, Eslami M, Malekafzali $H$, et al.Estimating the annual incidence of abortions in Iran applying a network scale-up approach. Iranian Red Crescent Medical Journal. 2014;16(10).

7. Bardos J, Hercz D, Friedenthal J, Missmer SA, Williams Z.A national survey on public perceptions of miscarriage. Obstetrics and gynecology. 2015;125(6):1313.

8. Moore $\mathrm{T}$, Parrish H, Black BP.Interconception care for couples after perinatal loss: a comprehensive review of the literature. The Journal of perinatal \& neonatal nursing. 2011;25(1):44-51.

9. Lee L, McKenzie-McHarg K, Horsch A.Women's decision making and experience of subsequent pregnancy following stillbirth. Journal of midwifery \& women's health. 2013;58(4):431-9.

10. Burden C, Bradley S, Storey C, Ellis A, Heazell AE, Downe $S$, et al.From grief, guilt pain and stigma to hope and pride-a systematic review and meta-analysis of mixed-method research of the psychosocial impact of stillbirth. BMC Pregnancy Childbirth. 2016;16(1):9.

11. Baghdari N, Sahebzad ES, Kheirkhah M, Azmoude E.The effects of pregnancy-adaptation training on maternal-fetal attachment and adaptation in pregnant women with a history of baby loss. Nursing and midwifery studies. 2016;5(2).

12. Fockler ME, Ladhani NNN, Watson J, Barrett JF, editors. Pregnancy subsequent to stillbirth: Medical and psychosocial aspects of care. Seminars in Fetal and Neonatal Medicine; 2017: Elsevier

13. Graham I, O'Connor A. User Manual-Preparation for Decision Making Scale [modified 2010]. Ottawa Hospital Research Institute. 2016.
14. Stacey D, Légaré F, Lewis K, Barry MJ, Bennett CL, Eden $\mathrm{KB}$, et al.Decision aids for people facing health treatment or screening decisions. Cochrane database of systematic reviews. 2017(4).

15. Gold KJ, Leon I, Chames MC.National survey of obstetrician attitudes about timing the subsequent pregnancy after perinatal death. American journal of obstetrics and gynecology. 2010;202(4):357. e1-. e6.

16. Allahdadian M, Irajpour AR.Educational Interventions Strategy to Promote the Health of Women Experienced Stillbirth. Journal of Holistic Nursing and Midwifery. 2019;29(1):1-7.

17. Wojcieszek AM, Boyle FM, Belizán JM, Cassidy J, Cassidy $\mathrm{P}$, Erwich $\mathrm{J}$, et al.Care in subsequent pregnancies following stillbirth: an international survey of parents. BJOG: An International Journal of Obstetrics \& Gynaecology. 2018;125(2):193-201.

18. Khezri R, Ravanipour M, Jahanpour F, Barekat M, Hosseini S.Empowerment in the self-management of hypertension: challenges from the perspective of Iranian elderly patients. Journal of Research and Health. 2017;7(1):603-13.

19. Baljani E, Salimi S, Rahimi J, Amanpour E, Parkhashjou M, Sharifnejad A, et al.The effect of education on promoting self efficacy in patients with cardiovascular disease. Journal of Kermanshah University of Medical Sciences (J Kermanshah Univ Med Sci). 2012;16(3):227-35.

20. Sahebzamani M, Fesharaki M, Abdollahi Mofrad Z.Association of life style and self-esteem among adolescent girls of daily public high schools of Tehran. Medical Science Journal of Islamic Azad Univesity-Tehran Medical Branch. 2010;20(1):45-51.

21. Roshan SN, Navipor H, Alhani F.The effect of family centered empowerment model on quality of life in adolescent girls with iron deficiency anemia. Yafteh. 2015;16(4):88-99.

22. O'connor A.User Manual-Decisional Conflict Scale. 1993 [updated 2010]. Ottawa: Ottawa Hospital Research Institute. 2014.

23. Ghiyasvandian S, Dehghan Nayeri N, Haghani H.The Effect of Decision Aid's Pakage in Selected Treatment by Patients with Early Stage Breast Cancer and Decision making Outcomes. Journal of Fasa University of Medical Sciences. 2013;3(3):271-9.

24. Moudi Z, Phanodi Z, Ansari H, Zohour MM.Decisional conflict and regret: shared decision-making about pregnancy affected by $\beta$-thalassemia major in Southeast of Iran. Journal of human genetics. 2018;63(3):309.

25. Envelope S.Randomisation and online databases for clinical trials. URL: https://www sealedenvelope com/[accessed 2019-03-08][WebCite Cache ID 76iYrkrIW]. 2019.

26. Yakubu I, Garmaroudi G, Sadeghi R, Tol A, Yekaninejad MS, Yidana A.Assessing the impact of an educational intervention program on sexual abstinence based on the health belief model amongst adolescent girls in Northern Ghana, a cluster randomised control trial. Reproductive Health. 2019;16(1):124.

27. Meade T, Dowswell E, Manolios N, Sharpe L.The motherhood choices decision aid for women with rheumatoid arthritis increases knowledge and reduces decisional conflict: a randomized controlled trial. BMC musculoskeletal disorders. 2015;16(1):260.

28. Carlson LM, Harris S, Hardisty EE, Hocutt G, Vargo D, Campbell E, et al.Use of a novel computerized decision aid for aneuploidy screening: a randomized controlled trial. Genetics in Medicine. 2019;21(4):923.

29. Clark Jr M.Community health nursing. Upper Saddle River. Community Health Nurses of Canada 15th ed Toronto: Community Health Nurses of Canada. 2011.

30. Ferreira C, Marques RC, Nicola P.On evaluating health centers groups in Lisbon and Tagus Valley: efficiency, equity and quality. BMC health services research. 2013;13(1):529. 
31. Amirabadi T, Nasiri A, Kazemi T, Kardan M.Educational needs of patients with heart valve replacement surgery in birjand, 2012. 2014;2(2):52-8.

32. Vahedian-Azimi A, Alhani F, Goharimogaddam K, Madani S, Naderi A, Hajiesmaeili M.Effect of family-centered empowerment model on the quality of life in patients with myocardial infarction: A clinical trial study. Journal of Nursing Education. 2015;4(1):8-22.

33. Seyed Nematollah Roshan F, Navipor H, Alhani F.Effect of Family-Centered Empowerment Model (FCEM) on quality of life of mothers having teenagers with iron deficiency anemia. Journal of Nursing Education. 2014;3(2):27-40.
34. Alhani F.Design and evaluation of family-centered empowerment model to prevent iron deficiency anemia. Tehran: Tarbiat modarres University. 2003.

35. Alhani F, Sh N, Kimiagar M, Kazemnezhad A, Heidarnia A.Designing of family based empowering model and evaluation of its effect on prevention of iron deficiency anemia in teenager girls. Pejouhandeh Journal. 2003;8(4):283-9.

36. Kheirkhah $M$, Vahedi $M$, Jenani P.The effect of group counseling on infertility adjustment of infertile women in Tabriz al-Zahra clinic. The Iranian Journal of Obstetrics, Gynecology and Infertility. 2014;17(113):7-14 